\title{
Operation of three-level inverter-based shunt active power filter under nonideal grid voltage conditions with dual fundamental component extraction
}

\begin{abstract}
In this paper, a new reference current generation method is proposed for effective harmonics mitigation and reactive power compensation of three-level neutral-point diode clamped inverterbased shunt active power filter (SAPF) under nonideal grid voltage conditions. The proposed method is named as dual fundamental component extraction algorithm. In operation, the proposed algorithm extracts at the same time, the desired fundamental current and voltage components for generating reference current and synchronization phases, respectively. As a result, the proposed algorithm is able to generate reference current that ensures in phase operation of SAPF with the operating power system, without depending on any phase-locked loop elements. Besides, the proposed algorithm employs self-tuning filter (STF) for accurate computation of the fundamental components. Design concept and effectiveness of the proposed algorithm are thoroughly studied and evaluated in MATLAB-Simulink. Additionally, a laboratory prototype utilizing TMS320F28335 digital signal processor is built to validate its feasibility. Encouraging findings obtained from both simulation and experimental works demonstrate effectiveness of the proposed algorithm under both ideal and nonideal grid voltage conditions.
\end{abstract}

Keyword: Active filters; Compensation; Digital signal processing chips; Harmonics suppression; Invertors; Power filters; Power grids; Reactive power; Synchronisation 